\title{
165 \\ WHICH IMAGING METHOD IS MORE EFFECTIVE IN LATERAL MASS SCREW PLACEMENT: O-ARM COMPUTED TOMOGRAPHY OR X-RAY?
}

\author{
(1) Mehmet Ozan Durmaz, (1) Mehmet Can Ezgü, (1) Gardaskhan Karımzada, (1) Adem Doğan \\ University of Health Sciences Turkey, Gülhane Training and Research Hospital, Clinic of Neurosurgery, Ankara, Turkey
}

\begin{abstract}
Objective: Although various surgical techniques have been described in the posterior cervical fixation, the lateral mass fixation method is the most preferred method. This study was conducted to examine the difference of imaging methods in order to detect and minimize important problems such as lateral mass fracture, vertebral artery foramen violation, and screw malposition intraoperatively during lateral mass fixation. Materials and Methods: Age, gender, etiological factors, intraoperative imaging method, number of fixed segments, and intraoperativepostoperative complications related to the surgical method of 41 patients were collected from the registered documents.

Results: Lateral mass fixation was performed in 41 patients. Of the patients $29.3 \%(n=12)$ were female and $70.7 \%(n=29)$ were male. When the etiological factors were examined, the most common cause was cervical spinal stenosis $(68.3 \%, \mathrm{n}=28)$. The patients were evaluated in two groups (A, B). A total of 280 lateral mass screws were placed in the patients in both groups. One hundred and twenty-nine (46.1\%) lateral mass screws were used in group A. One hundred and fifty-one (53.9\%) lateral mass screws were performed to 22 (53.7\%) patients in group B. Intraoperative screw revision rates were compared between the two groups using the chi-square test using SPSS 15.0 and no significant difference was found $(p<0.524)$.

Conclusion: No significant difference was found between X-ray and o-arm CT in terms of intraoperative screw revision. Both imaging methods can be used in lateral mass fixation. X-rays are inexpensive and readily available. However, tomography is expensive and requires experienced personnel, and it also increases the surgical time.
\end{abstract}

Keywords: Lateral mass fixation, $\mathrm{O}$-arm CT, X-ray, cervical fixation

\section{INTRODUCTION}

Posterior cervical spine fixation is a key component in posterior cervical arthrodesis, which is commonly performed to treat various degenerative, neoplastic, inflammatory and traumatic conditions affecting the cervical spine ${ }^{(1)}$. Posterior cervical fixation was based on wiring techniques in history. Wiring only offers stabilization for flexion, but does not immobilize the spine against the extension, lateral bending or rotation forces, which may put the fixation at high risk for mechanical failure ${ }^{(1)}$. Over time, more reliable methods such as interlaminar fixation, transfacet fixation, lateral mass fixation (LMF) and transpedicular fixation have been developed ${ }^{(1-3)}$. The most known method in posterior fixation is the LMF method $(4,5)$. The lateral mass screw fixation technique is commonly used for fixation of an unstable cervical spine caused by trauma, degenerative disorders, neoplasms, rheumatoid arthritis, and destructive spondyloarthropathy ${ }^{(6-9)}$. The LMF technique has emerged as a more reliable and easily applicable method compared to other methods ${ }^{(5)}$. Thereafter, several modifications have been suggested by many authors ${ }^{(10)}$. Currently, there is no standardized intraoperative method to estimate the trajectory angle of insertion of a lateral mass screw as proposed by the techniques described by An, Anderson, Magerl, or RoyCamille ${ }^{(11)}$. All these modifications aimed to improve the safety margin of this technique ${ }^{(10)}$. Their main considerations were vertebral artery injury, nerve root injury, facet joint violation, and fusion ${ }^{(12)}$. Fixation with a lateral mass screw also has its own difficulties. The anatomic structures at risk during lateral mass screwing of the cervical spine are the nerve roots, the vertebral artery, and the adjacent lateral masses ${ }^{(6,13-18)}$. Fluoroscopy, X-ray and O-arm computed tomography (CT) are used to evaluate intraoperative screw placement and malpositions during surgery. The importance of intraoperative $\mathrm{O}$-arm CT is increasing in order to avoid complications such as cervical nerve roots, spinal cord and vertebral artery damage,

Address for Correspondence: Adem Doğan, University of Health Sciences Turkey, Gülhane Training and Research Hospital, Clinic of Neurosurgery, Ankara, Turkey Phone: +90 3123045307 E-mail: drademdogan@yahoo.com Received: 01.10.2021 Accepted: 08.11.2021

ORCID ID: orcid.org/0000-0003-0933-6072 
especially due to screw malposition. We compared the patients who underwent LMF with intraoperative $\mathrm{X}$-ray and $\mathrm{O}$-arm CT in our clinic and examined the differences between the two intraoperative imaging methods.

\section{MATERIALS AND METHODS}

This study was approved by the University of Health Sciences Turkey, Gülhane Scientific Research Ethics Committee (number: 2021-238, date: 20.05.2021).

\section{Patient population}

In our study, patients who applied to our clinic with different etiologies and underwent posterior cervical fixation between September 1, 2016 and May 31, 2021 were examined. Demographic characteristics, clinical status, etiology, preoperative imaging, surgical method, and intra-postoperative complications of the patients were reviewed retrospectively.

Patients aged 18-80 years, who had posterior cervical instrumentation in our department were included in the study. Patients who had previous posterior cervical instrumentation, were outside the age range of 18-80 years and were re-operated due to post-surgical trauma or infection were excluded.

Age, gender, etiological factors, intraoperative imaging method, number of fixed segments, intraoperative-postoperative complications related to the surgical method of 41 patients were determined from the patient files. The patients were evaluated in two groups (A, B).

\section{Intraoperative İmaging}

Intraoperative $\mathrm{O}$-arm-CT or X-ray was used to examine conditions such as screw malposition, lateral mass fracture, and vertebral foramen violation in all cases, and the problematic cases were intervened again.

\section{Surgical Technique}

All patients were placed in prone position with the chest elevated $15^{\circ}$ to reduce venous bleeding and the neck in a neutral position to avoid fusion in rotation. The head is fixed into a three-pin head-holder allowing strong immobilization during screw placement. Lateral fluoroscopy is performed to confirm the level ${ }^{(19)}$.

After the lateral masses were revealed in all patients, the entry site was determined with the modified Magerl technique. Screw tracing was prepared with the help of high-speed drill. After the screw tracing was checked with the help of the guide, the screws with self-tapping feature were sent at an appropriate angle. We avoided placing the screws with the free-hand technique.

Screw position after delivery of lateral mass screws; It was checked with $\mathrm{O}$-arm-CT in patients in group $\mathrm{A}$, and with $\mathrm{X}$-rays in patients in group B. After evaluating the vertebral foramen, the tracing of the screws, and the condition of the lateral masses, suspicious or problematic situations were intervened. We did not use navigation in any of our cases.

\section{RESULTS}

29.3\% ( $n=12)$ of the cases were female and $70.7 \%(n=29)$ were male. The mean age of the cases was 53.2 years (19-76). When the etiological factors were examined, the most common cause was cervical spinal stenosis $(68.3 \%, \mathrm{n}=28)$. Apart from this, there were traumatic fractures and dislocations in $22 \%(n=9)$, tumor in $7.3 \%(n=3)$, and basilar invagination in $2.4 \%(n=1)$ (Table 1$)$. Long segment ( $\geqslant 3$ segments) instrumentation was performed in 33 patients $(80.5 \%)$ and short segment ( $<3$ segments) in 8 patients (19.5\%). A total of 280 lateral mass screws were placed in the patients in both groups at the first stage.

In the first stage, 129 lateral mass screws (46.1\%) were placed in 19 patients in group A (46.3\%). After control with intraoperative $\mathrm{O}$-arm-CT, a total of 2 screw malpositions (1.6\%) and 5 lateral mass fractures (3.9\%) were detected in 6 patients in this group, and the malpositioned screws were revised intraoperatively (Table 2). In this group, root damage was detected in 1 patient $(5.3 \%)$ in the postoperative period. Again in this group, an additional occipitocervical fusion was performed in 1 patient (5.3\%) to eliminate instability after screw malposition. No additional complications occurred in the patients in group A. In group A, intraoperative O-arm CT control was taken after the pins were placed in the segments to be fixed. The placement tracing of the screws was determined. Then the screw was placed. During screw placement, O-arm CT was taken again depending on the lateral mass status, superior and lateral angle of the screw, and the surgeon's experience. Revisions were made when necessary. Control CT was taken after all screws were placed. Fixation was completed.

In the first stage, 151 lateral mass screws (53.9\%) were placed in 22 patients in group B (53.7\%). After the control with intraoperative X-ray, a total of 1 screw malposition (0.7\%) was detected. And 5 lateral mass fractures (3.3\%) were suspected in 5 patients and revision was performed (Table 2). In this group, root damage was detected in 1 patient (4.5\%) in the postoperative period. An additional occipitocervical fusion was performed in 1 patient (4.5\%) to eliminate instability after screw malposition. No additional complications occurred in the patients in group B. For patients in group B, unilateral screws were placed in the segments to be fixed first. Superior

Table 1. Demographic and etiological factors of the cases

\begin{tabular}{lll}
\hline Characteristics & Number & $\%$ \\
\hline Sex & & \\
\hline Men & 29 & 70.7 \\
\hline Women & 12 & 29.3 \\
\hline Etiology & & \\
\hline Cervical stenosis & 28 & 28 \\
\hline Traumatic fracture & 9 & 22 \\
\hline Tumor & 3 & 7.3 \\
\hline Basilar invagination & 1 & 2.4
\end{tabular}


Table 2. Intraoperative and postoperative results of the cases

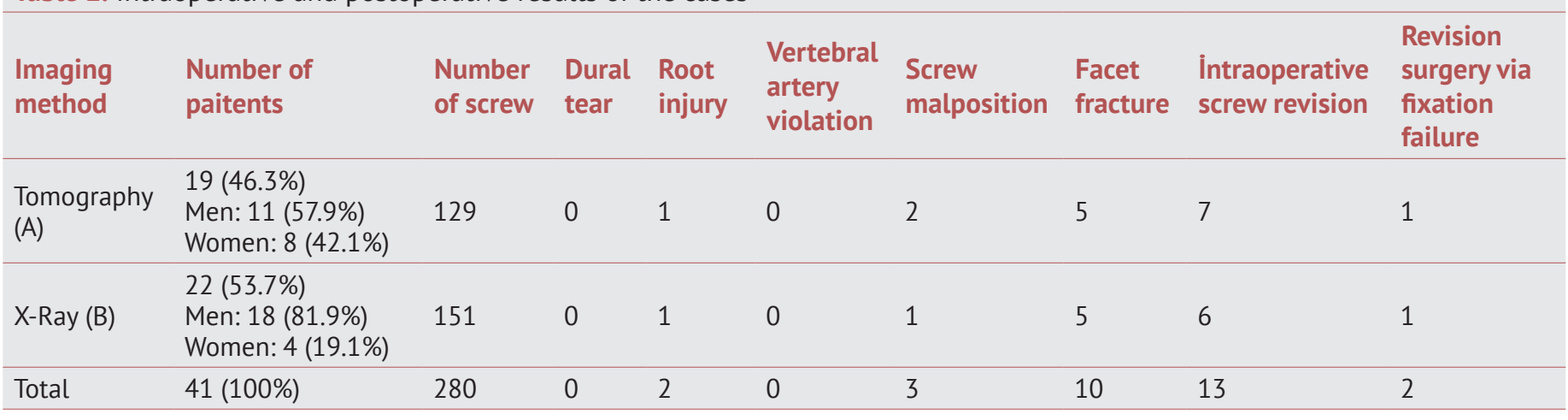

angles, lateral angles and lateral masses of the screws were checked with lateral and oblique X-rays. Revisions were made when necessary. Then, screws were placed on the opposite side of the same segments and similar procedures were repeated, and fixation was performed by completing bilateral screw placement.

A total of 10 lateral mass fractures (3.6\%) were detected in both groups due to screw placement. Of the 280 lateral mass screws placed, 13 screws (4.6\%) were revised due to intraoperative lateral mass fracture or screw malposition, root damage was detected in 2 patients (4.9\%), and occipitocervical fusion was performed in 2 patients (4.9\%) to ensure stability after screw malposition (Table 2). No additional complications developed in any of the patients apart from the stated complications.

In both groups, CT was taken within the first 4 hours postoperatively (Figure 1, 2). Neural foramen, vertebral artery foramen, spinal canal, lateral mass status and screw angle were evaluated by performing 3-D reconstruction. No problem requiring revision was detected in the $\mathrm{CT}$ taken in the postoperative period.

\section{Statistical Analysis}

Intraoperative screw revision was performed in 7 (5.4\%) of 129 lateral mass screws in 19 patients operated with 0 -arm, and in 6 (4\%) of 151 screws in 22 patients operated using X-ray. Intraoperative screw revision rates between the two groups were evaluated with the chi-square test using SPSS 15.0, no significant difference was found between the two groups $(p<0.524)$.

\section{DISCUSSION}

Posterior cervical fixation with lateral mass screws was first introduced by Roy-Camille in 1979; it has been increasingly used since that time to treat a wide range of cervical spine disorders ${ }^{(20)}$. The vast majority of surgeons hold the opinion that the LMF technique is the most optimal method for providing cervical stabilization after long segment decompression(21). Lateral mass screw fixation has advantages over standard posterior wiring techniques; it can be done easily for many levels on patients with laminectomy and it can preserve the biomechanical forces ${ }^{(22)}$. Although the LMF method is the most

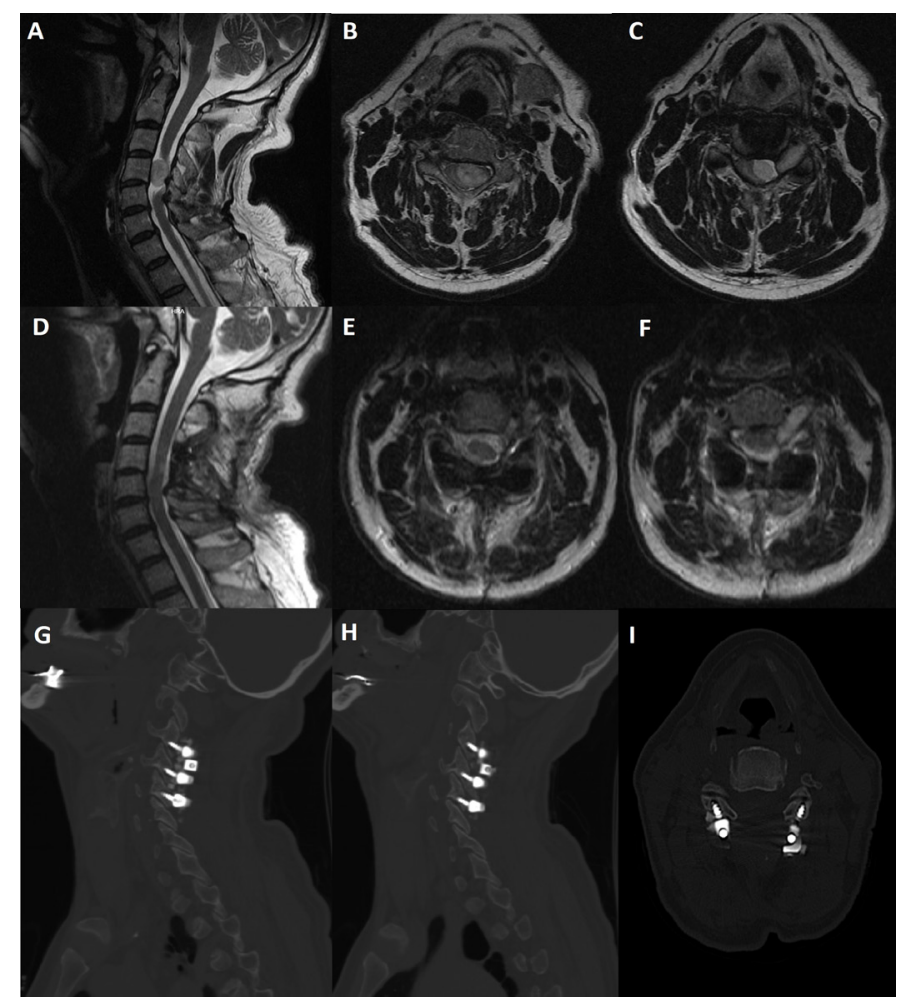

Figure 1. T2-weighted sagittal and axial images show a intradural extramedullary mass lesion which was histopathologically diagnosed as schwannoma at C4 level (A, B) with foraminal extension (C). Postoperative MRI images reveal adequate decompression and total excision of the tumor inside the spinal canal $(D, E)$. Residual lesion and slight root edema is also shown (F). Proper lateral mass screw position which was checked intraoperatively through X-ray was confirmed with computerized tomography images postoperatively $(\mathrm{G}, \mathrm{H}, \mathrm{I})$

MRI: Magnetic resonance imaging

reliable and frequently preferred method among surgeons, it has significant complications. Lateral mass plate and screw devices have proven to be safe despite their proximity to neurovascular structures. However, posterior plate-screw techniques can be associated with potential problems, including injury to the vertebral artery, nerve roots, facet joints and spinal cord ${ }^{(6,14-18)}$. 


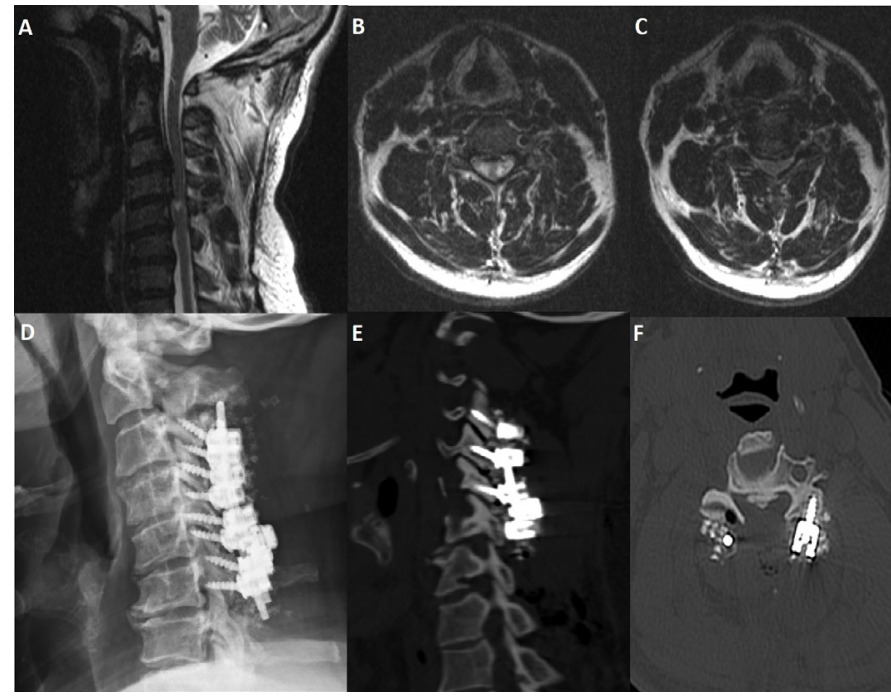

Figure 2. Loss of cervical lordosis, multi-level degenerative disc disease, cervical spinal stenosis and myelomalacia at $C 5$ level can be seen T2-weighted sagittal and axial images (A, B, C). The patient underwent multi-level cervical laminectomy and lateral mass screw fixation surgery. O-arm imaging system was used to confirm screw placements intraoperatively. Plain radiography and computerized tomography images revealed that the screw placements were accurate $(D, E, F)$

In the literature, the rate of intraoperative lateral mass fracture has been reported as $1.6-4.7 \%{ }^{(6)}$. Inoue et al.(4) Reported the overall incidence of lateral mass fracture was $4.7 \%$ in his retrospective study of 117 consecutive patients undergoing lateral mass screw fixation by a modified Magerl's technique. In our study, the rate of lateral mass fracture was found to be $3.6 \%$. Another complication encountered in posterior cervical fusion surgeries where lateral mass screws are used is damage to the cervical nerve roots. The anatomic study of $\mathrm{An}$ et al.(6) observed that the nerve root's exit point was at the anterolateral portion of the superior facet. According to the LMF technique used, the rate of damage to the cervical roots differs. Heller et al. ${ }^{(23)}$ is compared the anatomic risks between the Roy-Camille and Magerl techniques. They found that the Roy-Camille screws were associated with less risk of nerve root injury, but more chance of facet joint violation. In contrast, the Magerl screws were associated with more risk of nerve root injury, but less chance of facet joint violation ${ }^{(23)}$. Baek et al.(24) reported one nerve root injury was observed in each cervical spine segment using the Roy-Camille method (8.3\%) and the Magerl method (5.6\%) in his cadaveric study. Jeanneret et al.(9) has reported only two cases of nerve root-related problems in their total 51 patients. In our study, cervical root damage was detected in only 2 patients (4.9\%) out of 41 patients 1 in group A (5.3\%) and 1 in group $B(4.5 \%)$. When the postoperative CT images of the patients with root damage in both groups were examined, it was observed that the screws did not protrude beyond the lateral mass and into the neural foramen, and it was concluded that they were independent of the screw trajectory.
Vertebral artery injury remains a major concern; however, the reported prevalence rate is negligible ${ }^{(16,17,25)}$. Kim et al.(26) reported in a prospective study on the evaluation of 1256 lateral mass screws positioned in 178 consecutive patients at their institution. One screw revealed in the follow-up CT violating the foramen transversarium without penetrating the vertebral artery required no further intervention ${ }^{(26)}$. Ebraheim et al. ${ }^{(27)}$ reported his study, $\mathrm{C} 6$ has a greater risk for vertebral artery injury. In our study, intraoperative vertebral artery damage was not detected in any patient. Considering that LMF is frequently used today, it is clear that the complications that will occur are directly related to the increasing number of cases.

There are many advantages to using $O$ arm CT during intraoperative imaging. That provides us with various parameters including trajectory, diameter and lengths of virtual screws. Screw placement in cases is performed with direct guidance without the need to rely only on anatomical signs. However, it is difficult to implement because it is expensive, requires experienced personnel and is not available in every center. In repeated imaging, the amount of radiation received by the patient and the surgical team increases ${ }^{(28)}$.

Intraoperative $\mathrm{X}$-ray imaging is an easily applicable and ubiquitous method without prolonging the operation time. The amount of radiation received by the patient and the surgical team is lower compared to O-arm CT. However, it is difficult to provide effective intraoperative imaging in patients with overweight, short neck and cervical spine degeneration ${ }^{(25-27)}$.

In our study, we tried to determine the safer imaging method by examining the relationship between intraoperative imaging method and possible complications in cases with LMF and to determine the differences between the two imaging methods we preferred. Also, we have not encountered a study in the literature examining the differences between $\mathrm{O}$ arm $\mathrm{CT}$ and $\mathrm{X}$-ray supported lateral mass screw placement. In both groups, we found that revision was not required after postoperative $\mathrm{CT}$ in the early period. Postoperative CT controls of patients using $\mathrm{X}$-ray when compared to postoperative $\mathrm{CT}$ control of patients using $\mathrm{O}$-arm $\mathrm{CT}$, the rates of lateral mass fracture, vertebral artery foramen and neural foramen violation were found to be similar.

\section{Study Limitations}

There are some limitations in our study. The first is the low number of cases. Secondly, since it is a retrospective study, the data were analyzed over the files and the unsaved data of the patients could not be reached. Another limitation is that the BMD status of the patients was not known, so it could not be clearly evaluated whether the facet fracture was due to technical reasons or low bone quality.

\section{CONCLUSION}

Cervical posterior fusion surgery using a lateral mass screw is one of the most used methods in posterior cervical instrumentation. In order to minimize intraoperative risks, 
intraoperative screw positions should be visualized in the most optimal way. For this reason, it is used both as an $\mathrm{O}$-arm-CT and $X$-ray imaging method in the intraoperative process. Because of its ubiquity and inexpensive access, X-ray is used more frequently than $\mathrm{O}$-arm-CT, which is more expensive and can be time-consuming to set up intraoperatively. However, they are similar in effectiveness.

\section{Ethics}

Ethics Committee Approval: This study was approved by the University of Health Sciences Turkey, Gülhane Scientific Research Ethics Committee (number: 2021-238, date: 20.05.2021).

Informed Consent: Retrospective study.

Peer-reviewed: Internally peer-reviewed.

\section{Authorship Contributions}

Concept: M.O.D., M.C.E., G.K., Design: M.C.E., Data Collection or Processing: M.C.E., Analysis or Interpretation: G.K., Literature Search: M.O.D., A.D., Writing: G.K., A.D.

Conflict of Interest: There is no conflict of interest was declared by the authors.

Financial Disclosure: The authors declared that this study received no financial support.

\section{REFERENCES}

1. Joaquim AF, Tan L, Riew KD. Posterior screw fixation in the subaxial cervical spine: a technique and literature review. I Spine Surg. 2020;6:252-61.

2. Klekamp JW, Ugbo JL, Heller JG, Hutton WC. Cervical transfacet versus lateral mass screws: a biomechanical comparison. J Spinal Disord. 2000; 13:515-8.

3. Joaquim AF, Mudo ML, Tan LA, Riew KD. Posterior subaxial cervical spine screw fixation: a review of techniques. Global Spine J. 2018;8:751-60.

4. Inoue S, Moriyama T, Tachibana T, Okada F, Maruo K, Horinouchi $Y$, et al. Risk factors for intraoperative lateral mass fracture of lateral mass screw fixation in the subaxial cervical spine. J Neurosurg Spine. 2014;20:11-7.

5. Hamdan ARK, Mahmoud RN, Al Mamoun MM, El Khateeb EES. Effect of sub-axial cervical lateral mass screw fixation on functional outcome in patients with cervical spondylotic myelopathy. Asian J Neurosurg. 2019; 14:140-1.

6. An HS, Gordin R, Renner K. Anatomic considerations for plate-screw fixation of the cervical spine. Spine (Phila Pa 1976). 1991;16(Suppl 10):S548-51.

7. Aydogan M, Enercan M, Hamzaoglu A, Alanay A. Reconstruction of the subaxial cervical spine using lateral mass and facet screw instrumentation. Spine (Phila Pa 1976). 2012;37:E335-41.

8. Inoue S, Moriyama T, Tachibana T, Okada F, Maruo K, Horinouchi Y, et al. Cervical lateral mass screw fixation without fluoroscopic control: analysis of risk factors for complications associated with screw insertion. Arch Orthop Trauma Surg. 2012;132:947-53.

9. Jeanneret B, Magerl F, Ward EH, Ward JC. Posterior stabilization of the cervical spine with hook plates. Spine (Phila Pa 1976). 1991;16(Suppl 3):S56-63.
10. Rathinavelu S, Islam A, Shivhare P, Chatterjee S. Lateral mass screw fixation in the cervical spine: introducing a new technique. Asian Spine J. 2020 Nov 16. doi: 10.31616/asj.2020.0143. Epub ahead of print.

11. Chin KR, Eiszner JR, Roh JS, Bohlman HH. Use of spinous processes to determine drill trajectory during placement of lateral mass screws: a cadaveric analysis. J Spinal Disord Tech. 2006;19:18-21.

12. Barrey C, Mertens P, Jund J, Cotton F, Perrin G. Quantitative anatomic evaluation of cervical lateral mass fixation with a comparison of the Roy-Camille and the Magerl screw techniques. Spine (Phila Pa 1976). 2005;30:E140-7. doi: 10.1097/01.brs.0000155416.35234.a3.

13. Xu R, Ebraheim NA, Klausner T, Yeasting RA. Modified Magerl technique of lateral mass screw placement in the lower cervical spine: an anatomic study. J Spinal Disord. 1998;11:237-40.

14. Xu R, Haman SP, Ebraheim NA, Yeasting RA. The anatomic relation of lateral mass screws to the spinal nerves. A comparison of the Magerl, Anderson, and An techniques. Spine (Phila Pa 1976). 1999;24:2057-61.

15. Ebraheim NA, Klausner T, Xu R, Yeasting RA. Safe lateral-mass screw lengths in the Roy-Camille and Magerl techniques. An anatomic study. Spine (Phila Pa 1976). 1998;23:1739-42.

16. Graham AW, Swank ML, Kinard RE, Lowery GL, Dials BE. Posterior cervical arthrodesis and stabilization with a lateral mass plate. Clinical and computed tomographic evaluation of lateral mass screw placement and associated complications. Spine (Phila Pa 1976). 1996;21:323-8; discussion 329.

17. Heller JG, Silcox DH 3rd, Sutterlin CE 3rd. Complications of posterior cervical plating. Spine (Phila Pa 1976). 1995;20(22):2442-8.

18. Jónsson H Jr, Rauschning W. Anatomical and morphometric studies in posterior cervical spinal screw-plate systems. J Spinal Disord. 1994;7:429-38.

19. Tessitore E, El-Hassani Y, Schaller K. How I do it: cervical lateral mass screw fixation. Acta Neurochir (Wien). 2011;153:1695-9.

20. Feng S, Lin J, Su N, Meng H, Yang Y, Fei Q. 3-Dimensional printing templates guiding versus free hand technique for cervical lateral mass screw fixation: a prospective study. J Clin Neurosci. 2020;78:252-8.

21. Rehman L, Bukhari I, Afzal A, Rizvi R. Lateral mass screw fixation in cervical spine injury. Pak J Med Sci. 2017;33:1355-9.

22. Al Barbarawi MM, Audat ZA, Obeidat MM, Qudsieh TM, Dabbas WF, Obaidat $\mathrm{MH}$, et al. Decompressive cervical laminectomy and lateral mass screw-rod arthrodesis. Surgical analysis and outcome. Scoliosis. 2011;6:10

23. Heller JG, Carlson GD, Abitbol II, Garfin SR. Anatomic comparison of the Roy-Camille and Magerl techniques for screw placement in the lower cervical spine. Spine (Phila Pa 1976). 1991;16(Suppl 10):S552-7.

24. Baek JW, Park DM, Kim DH. Comparative analysis of three different cervical lateral mass screw fixation techniques by complications and bicortical purchase : cadaveric study. J Korean Neurosurg Soc 2010;48:193-8.

25. Wellman BJ, Follett KA, Traynelis VC. Complications of posterior articular mass plate fixation of the subaxial cervical spine in 43 consecutive patients. Spine (Phila Pa 1976). 1998;23:193-200.

26. Kim HS, Suk KS, Moon SH, Lee HM, Kang KC, Lee SH, et al. Safety evaluation of freehand lateral mass screw fixation in the subaxial cervical spine: evaluation of 1256 screws. Spine (Phila Pa 1976). 2015;40:2-5

27. Ebraheim NA, Xu R, Yeasting RA. The location of the vertebral artery foramen and its relation to posterior lateral mass screw fixation. Spine (Phila Pa 1976). 1996;21:1291-5.

28. Wang YC, Zhou ZZ, Wang B, Zhang K, Chen H, Chen KW, et al. Occipitocervical fusion via cervical pedicle fixation assisted with o-arm Navigation. Orthop Surg. 2020;12:1100-7. 